\title{
Article \\ The Nasal Epithelium as a Route of Infection and Clinical Signs Changes, in Rainbow Trout (Oncorhynchus mykiss) Fingerlings Infected with Aeromonas spp.
}

\author{
Fabián Ricardo Gómez de Anda ${ }^{1}$ (D), Vicente Vega-Sánchez ${ }^{1}$, Nydia Edith Reyes-Rodríguez ${ }^{1}$, \\ Víctor Manuel Martínez-Juárez ${ }^{1}$, Juan Carlos Ángeles-Hernández ${ }^{1}{ }^{10}$, Ismael Acosta-Rodríguez ${ }^{2}$, \\ Rafael German Campos-Montiel ${ }^{1, *}$ and Andrea Paloma Zepeda-Velázquez ${ }^{1, *}$ (])
}

1 Instituto de Ciencias Agropecuarias, Universidad Autónoma del Estado de Hidalgo, Av. Universidad km 1. Ex-Hda. de Aquetzalpa A.P. 32 CP., Tulancingo 43600, Hidalgo, Mexico; fabian_gomez9891@uaeh.edu.mx (F.R.G.d.A.); vicente_vega11156@uaeh.edu.mx (V.V.-S.); nydia_reyes@uaeh.edu.mx (N.E.R.-R.); victormj@uaeh.edu.mx (V.M.M.J.); juan_angeles@uaeh.edu.mx (J.C.Á.-H.)

2 Facultad de Ciencias Químicas, Universidad Autónoma de San Luis Potosí, Av. Dr. Manuel Nava, No. 6. Zona Universitaria. C.P., San Luis Potosí 78320, Mexico; iacosta@uaslp.mx

check for

updates

Citation: Gómez de Anda, FR.; Vega-Sánchez, V.; Reyes-Rodríguez, N.E:

Martínez-Juárez, V.M.;

Ángeles-Hernández, J.C.;

Acosta-Rodríguez, I.;

Campos-Montiel, R.G.;

Zepeda-Velázquez, A.P. The Nasal Epithelium as a Route of Infection and Clinical Signs Changes, in

Rainbow Trout (Oncorhynchus mykiss) Fingerlings Infected with Aeromonas spp.. Appl. Sci. 2021, 11, 9159. https://doi.org/10.3390/app11199159

Academic Editors: Panagiotis Berillis and Božidar Rašković

Received: 25 August 2021

Accepted: 28 September 2021

Published: 1 October 2021

Publisher's Note: MDPI stays neutral with regard to jurisdictional claims in published maps and institutional affiliations.

Copyright: () 2021 by the authors Licensee MDPI, Basel, Switzerland. This article is an open access article distributed under the terms and conditions of the Creative Commons Attribution (CC BY) license (https:// creativecommons.org/licenses/by/ $4.0 /)$
* Correspondence: rcampos@uaeh.edu.mx (R.G.C.-M.); andrea_zepeda@uaeh.edu.mx (A.P.Z.-V.); Tel.: +52-72-2247-8295 (R.G.C.-M. \& A.P.Z.-V.)

Abstract: The genus Aeromonas is a group of bacteria that is widely distributed in water bodies and belongs to the normal intestinal microbiota of aquatic and terrestrial animals. In the present work, rainbow trout fingerlings were experimentally infected by an immersion bath with different Aeromonas species. Subsequently, the behavior of the infected groups was observed and recorded. Infected fingerlings were evaluated by histopathology. The highest percentages of hyperpigmentation $(18.88 \%)$ and inappetence $(47.7 \%)$ were observed in fish infected with A. salmonicida, while abnormal swimming (83.33\%) was recorded in fish infected with A. bestiarum. In histopathological findings, the highest percentages were observed in the olfactory epithelium (50.0\%) for A. lusitana and A. salmonicida (41.1\%)-infected fish. While, in the nervous system, the cerebral hemispheres (31.1\%) in A. media-infected fish and the oblongata medulla (40.0\%) in the A. bestiaruminfected fish presented the highest percentages. Meanwhile, A. salmonicida and A. bestiarum have the highest pathogenicity and virulence based on the histopathological findings in the olfactory epithelium and nervous system. Due to the proximity of the olfactory epithelium with the nervous tissue, it is possible that the infection generated by the Aeromonas species and the histopathological findings in the nervous tissue are reflected in different behavioral changes that suggest differences in the pathogenicity and virulence of the bacteria.

Keywords: Aeromonas spp.; rainbow trout; histopathology; bacteria; infection

\section{Introduction}

The genus Aeromonas is a group of bacteria of importance to aquaculture, which is frequently isolated in aquatic environments [1,2]. They can act as important pathogens in poikilotherm species because they are widely distributed in water bodies [3], and they are part of the normal gut microbiota of aquatic and terrestrial animals [4]. They have zoonotic potential, high pathogenic potential, and the ability to adapt to different environments [5]. Currently, 36 genetically identified Aeromonas species are known and isolated from aquatic environments [6]. This genus is divided into two groups: an immobile group, with $A$. salmonicida being the main species, and a mobile group that contains the rest of the Aeromonas species [5]. A. bestiarum, A. caviae, A. hydrophila, A. piscicola, A. salmonicida, and $A$. veronii are reported to be the species that are mostly isolated from pathological conditions in salmonids [7]. Aeromonas infection in different species of fish can occur at 
different ages of those fish that are susceptible to the disease, the presentation of stress in the fish is an important factor for the development of the disease, however the participation of external factors such as changes in water temperature, large amounts of excreta in ponds, overcrowding, and others can favor the presentation of the disease [3,5].

The pathology associated with the infection of $A$. Salmonicida, A. hydrophila, A. bestiarum, and $A$. veronii in rainbow trout includes septic processes, the colonization of liver tissue and mortality [8], fish can develop exophthalmos, ocular ulceration, anorexia, the clinical signs included dermis lesion (ulcers, erosion, hemorrhage, darkened skin, loss of scales, furunculosis, and others), abdominal distension, fin rot, and in some cases, premaxilla bone exposition can be observed [1,8-10]. Infected young fish modify their behavior, including jumping out of the pond, the darkening of the skin, abnormal swimming, low swimming, lethargy and inappetence $[1,5,11]$. Sometimes, bloody discharge from the nostrils and death occurs [12]. In the fish into the nasal cavity, the olfactory organ or olfactory rosette, or just rosette is a chemosensory system, which are composed by pseudostratified epithelium with sensory (olfactory sensory neurons) and mucosal areas (goblet cells), on the lamina propria of the rosette are localized the terminal axons [13,14].

However, studies focused on nasal infection in Aeromonas have not been investigated. Bartkova et al. [15] carried out an infection in rainbow trout intraperitoneally with A. salmonicida and through real-time monitoring by bioluminescence, it was established that the colonization sites, were dorsal and pectoral fins; gills, stomach, intestine, anus; as well as the oral, nasal and eye cavity, these sites being the first to be exposed to the aquatic environment, as well as the skin. Currently, the immunization of fish against Aeromonas is carried out by intraperitoneal injection or by immersion bath [6]. Recently, the nasal route of Yersinia ruckeri was demonstrated as an entry point for bacteria to establish, infect and spread through the nervous system, which in turn causes erratic swimming and exophthalmia [16]. This suggests that pathogenic and virulent bacteria can cause nervous problems that affect behavior. On the other hand, the use of the nasal route as a vaccination route was investigated as an alternative for the immunization in teleost fish, on the case of rainbow trout, it was used as a biological model for the challenge with infectious hematopoietic necrosis virus [13].

The aim of the present research was to identify the presence of histopathological lesions observed in the rosette and nervous tissue, to identify a relation between the nasal tissue and nervous tissue with fish behavior, in rainbow trout fingerlings, experimentally infected with different Aeromonas species.

\section{Materials and Methods}

\subsection{Ethics Statement}

This experimental infection was approved by the Bioethics Commission and Animal Welfare Committee (Comisión de Bioética y Bienestar animal, CBBA) of the Facultad de Medicina Veterinaria y Zootecnia (FMVZ), Universidad Autónoma del Estado de México (UAEMex) 012-2012. A total of 1200 rainbow trout were obtained from a trout farm (El Zarco, Ocoyoacac, Mexico), previously reported by Zepeda-Velázquez and colleagues [8].

\subsection{Animals and Husbandry}

For the acclimation period, 1200 fish ( $3-5 \mathrm{~cm}$ and 2-3 $\mathrm{g}$ of weight) were maintained in 100-L (L) containers, as previously reported by Zepeda-Velázquez and colleagues [8]. A total of 120 fish, 30 for the control group and 90 for the three replicas of each experimental infection, were randomly distributed in a $6 \mathrm{~L}$ glass aquarium equipped with aeration (air pump ELITE 799), air stones positioned at opposite front ends of the aquarium and fresh water without chlorine. An immersion bath with 10 different Aeromonas species was performed at a bacterial concentration of $1.5 \times 10^{8}$ colony-forming units (CFU)/milliliter $(\mathrm{mL})$ for $1 \mathrm{~h}$ in a $6 \mathrm{~L}$ glass aquarium with aeration; all groups were immersed independently [8]. For the maintenance and propagation of bacterial isolates, Farto and their colleagues' methodology was used [17]. After the immersion bath, rainbow trout fingerlings were 
put in a new $6 \mathrm{~L}$ glass aquarium with the same characteristics as mentioned above, and all glass aquarium were isolated by a plastic separation, to observe independent behavior between fishes in glass aquarium. The maintenance of the glass aquarium included $40 \%$ water replacement, feeding, and elimination of biological sediment, including feces and food rest. Fish were observed daily, and moribund fish and those with clinical signs were euthanized by an overdose of tricaine methane sulfonate (MS222; Finquel) [12].

\subsection{Behavioral Observations and Clinical Signs}

The evaluated behaviors are listed in Table 1 . The experimental period lasted a total of 14 days [8]. For the first $5 \mathrm{~h}$ post-infection (pi) and all 14 days, all fish were observed for 10-15 min [18], and the number of fish that present behavioral modification were counted and register before maintenance. Moribund fish and those with severe clinical signs were immediately euthanized [8].

Table 1. Aeromonas species and histopathological lesions observed in nasal epithelium or rosette, telencephalon, and oblongata medulla changes (\%), observed in rainbow trout fingerlings infected with Aeromonas spp.

\begin{tabular}{ccc}
\hline Behavior or Clinical Sign & Definition & Reference(s) \\
\hline Loss of appetite & $\begin{array}{c}\text { Fish refuse to eat and/or lose interest in food (anorexia) } \\
\text { Loss of consistency, regularity and/or uniformity in } \\
\text { movement; fish swimming in different directions }\end{array}$ & {$[12,17,19-21]$} \\
Abnormal swimming (Erratic swimming) & $\begin{array}{c}\text { Fingerlings show an excess of melanin pigmentation in } \\
\text { the skin, giving them a darker color }\end{array}$ & {$[17,22]$} \\
Hyperpigmentation and/or darkened skin & \begin{tabular}{c}
{$[1,9,12,23]$} \\
\hline
\end{tabular}
\end{tabular}

\subsection{Histopathological Studies}

Fish were fixed in $10 \%$ (volume/volume) neutral buffered formalin ( $\mathrm{pH} 7.4$ ), embedded in paraffin, and stained with hematoxylin and eosin $[8,10]$.

\subsection{Statistical Analysis}

Data were analyzed with SPSS software (version 21, IBM Inc. Chicago, IL, USA). Differences in the percentages of behaviors, clinical signs and histopathological lesions in the rosette, telencephalon and medulla oblongata were analyzed using a Chi-square test (significance at $p<0.05$ ) [18]. Differences between isolates of each behavior and clinical sign were determined using Tukey's multiple comparison tests, with a significance level of $p<0.05$ [24].

Two independent correspondence analyses (CA) were implemented with the aim of establishing whether histopathological lesions and behavioral changes depend on Aeromonas species through a graphical display of their relationship. The CA were carried out in the package FactoMineR version 2.3 [25], of the statistical program $R$ version 4.0.2. (R core team, 2016) [26] and its graphical representation was through a biplot drawn in the FactoExtra package [27]. The biplot approximates the distribution of a multivariate sample in a generally two-dimensional reduced-dimension space, where angles and proximity among variables provide a measure of association.

\section{Results}

\subsection{Behaviors and Clinical Signs}

The experimental infection process was separated from the 5-hour feed period for all groups. Fish infected with $A$. salmonicida, A. veronii, A. bestiarum, A. hydrophila, A. caviae and $A$. sobria showed at least one change in the evaluated behaviors or clinical sign. The presentation of darkening of the skin in fish infected with $A$. salmonicida $(18.8 \%)$, A. veronii $(15.5 \%)$ and, A. hydrophila (11.1\%) was observed with statistical differences; meanwhile fingerlings infected with $A$. allosaccharophila, A. bestiarum, A. caviae, A. lusitana, A. media, A. popoffii, A. sobria, and the control group, did not present color changes $(p>0.05)$ (Table 1$)$ (Figure 1a). 




(a)

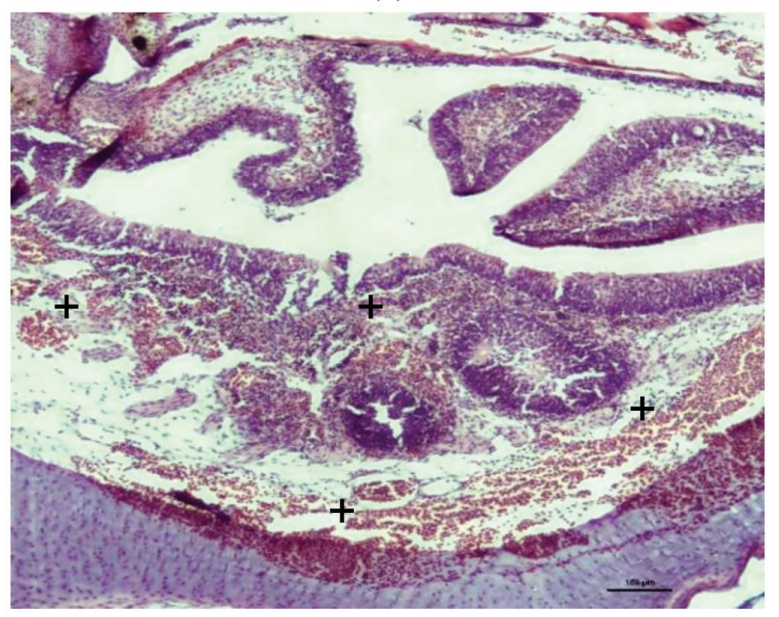

(c)

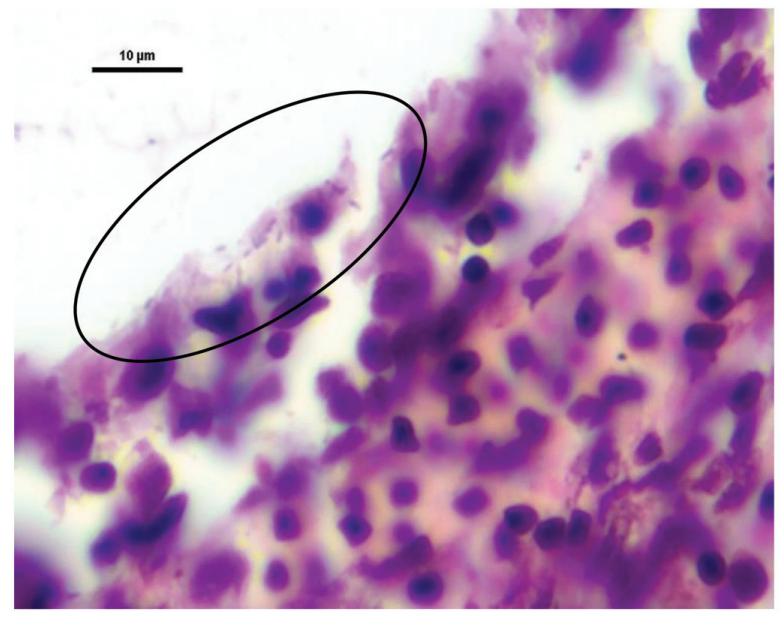

(e)



(b)

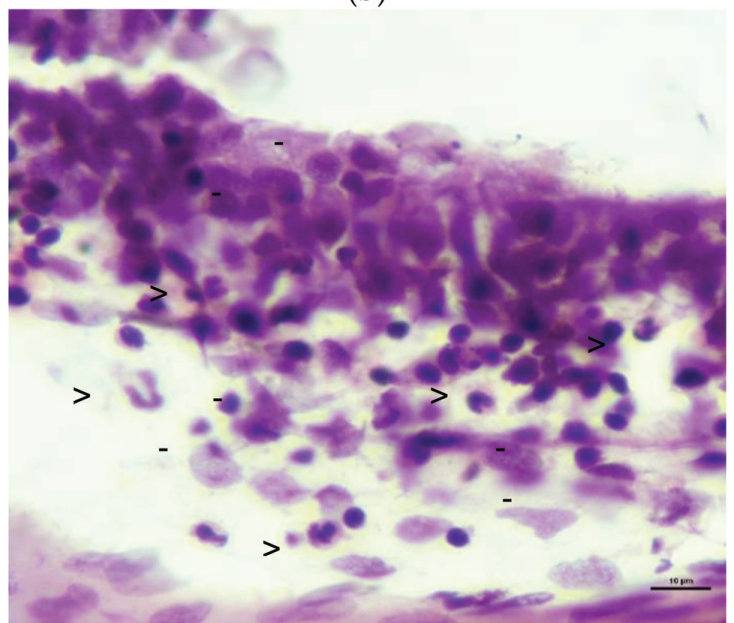

(d)



(f)

Figure 1. Rainbow trout fingerlings experimental infected by immersion with different Aeromonas species. (a) Fingerlings control group. Bar = $1 \mathrm{~cm}$; (b) Fingerlings present different darkening skin grades (asterisk), infected with $A$. salmonicida . Bar = $1 \mathrm{~cm}$; (c) nasal epithelium, moderate edematous and severe hemorrhagic rhinitis (plus sign) on fingerlings infected with A. lusitana; (d) nasal epithelium, suppurative rhinitis in fingerlings infected with A. salmonicida, neutrophil (greater-than sing) and macrophage (hyphen-minus) infiltration were observed; (e) nasal epithelium with bacterial shapes on the surface (circle), in fingerlings infected with A. salmonicida; and, (f) oblongata medulla, slight focal myelitis (asterisk) in fingerlings infected with $A$. hydrophila. 
The lack of appetite or inappetence in fingerlings infected with $A$. salmonicida $(47.7 \%)$, A. hydrophila and A. sobria (46.6\%), A. caviae (38.8\%) and, A. bestiarum (32.2\%), was observed with a statistical difference $(p>0.05)$ for A. allosaccharophila, A. lusitana, A. media, A. popoffii, $A$. veronii, and the control group, who showed no changes in their feeding behavior or feeding regulation. Finally, fingerlings infected with $A$. bestiarum (83.3\%), A. hydrophila $(74.4 \%)$, A. sobria (67.7\%), A. salmonicida (66.6\%) and, A. caviae showed erratic behavior changes, a loss of consistency and a loss of swimming uniformity. No significant statistical differences $(p>0.05)$ were noted for the A. allosaccharophila, A. lusitana, A. media, A. popoffii and $A$. veronii groups or the control group (Table 2).

Table 2. Percentages of clinical signs or behavioral changes, present in fingerlings experimentally infected with different Aeromonas species.

\begin{tabular}{ccccc}
\hline & & \multicolumn{2}{c}{ \% of Fish with Clinical Sign or Behavioral Changes $\mathbf{1}^{\mathbf{1}}$} \\
\cline { 3 - 5 } Aeromonas Species & $\mathbf{N}$ & $\begin{array}{c}\text { Darkened } \\
\text { Skin/Hyperpigmentation }\end{array}$ & $\begin{array}{c}\text { Lack of } \\
\text { Appetite/Inappetence }\end{array}$ & Abnormal Swimming \\
\hline A. allosaccharophila & 90 & 0 & 1.11 & 25.55 \\
A. bestiarum & 90 & 6.66 & 32.22 & 83.33 \\
A. caviae & 90 & 0 & 38.88 & 60 \\
A. hydrophila & 90 & 11.11 & 46.66 & 74.44 \\
A. lusitana & 90 & 0 & 1.11 & 34.44 \\
A. media & 90 & 1.11 & 16.66 & 25.55 \\
A. popoffii & 90 & 0 & 3.33 & 31.11 \\
A. salmonicida & 90 & 18.88 & 47.7 & 66.66 \\
A. sobria & 90 & 1.11 & 46.66 & 67.77 \\
A. veronii & 90 & 15.55 & 28.88 & 38.88 \\
Control group & 90 & 0 & 0 & 8.88 \\
\hline
\end{tabular}

${ }^{1}$ Groups in italics within the same column are significantly different $(p<0.05)$.

\subsection{Histopathological Lesions in Nasal and Nervous Tissue}

In the nasal epithelium, a significant number of fingerlings infected with A. lusitana (50\%) and A. salmonicida (41.1\%) showed different histopathological lesions. Congestion with different distribution patterns and high severity grades, focal hemorrhagic epithelium (Figure 1b), moderate multifocal epithelium and hyperplasia of the nasal epithelium and goblet cells, as well as a leukocyte infiltrate of mononuclear and polymorphonuclear cells, were observed (Figure 1c). On the other hand, the histopathological finds of $A$. media (35.5\%), A. allosaccharophila (30\%), A. caviae (28.8\%), A. hydrophila (27.7\%), A. bestiarum $(26.6 \%)$, A. sobria (20\%), A. veronii $(11.1 \%)$, and $A$. popoffii $(7.7 \%)$, present middle-to-less severity and distribution; edema, congestion, goblet cell hyperplasia and, leucocyte infiltration in different grades and, different distributions in the nasal epithelium were observed, with no significant histopathological lesions $(p>0.05)$. Histopathological lesions in control group were not observed (Table 3 ). Basophilic aggregates or bacterial aggregations were observed in all fishes experimentally infected with the different Aeromonas species. Basophilic aggregates or bacterial aggregations in the control group was not observed.

The main histopathological lesion in the telencephalon consisted of severe multifocal congestion for fish infected with $A$. media (31.1\%), and a moderate degree for the groups infected by $A$. salmonicida $(25.5 \%)$, and $A$. caviae $(22.2 \%)$. The congestion was observed in focal and multifocal presentation, and also hemorrhagic lesions were present on focal and bifocal distribution, in moderate-to-slight presentation in $A$. bestiarum $(21.1 \%), A$. hydrophila and A. lusitana (18.8\%). No significant histopathological changes were observed in A. veronii (10\%), A. sobria (7.7\%), A. allosaccharophila, and A. popoffii (3.3\%), and control groups (Table 3 ). 
Table 3. Aeromonas species and histopathological lesions observed in nasal epithelium or rosette, telencephalon, and oblongata medulla changes (\%), observed in rainbow trout fingerlings infected with different Aeromonas species.

\begin{tabular}{ccccc}
\hline \multirow{2}{*}{$\begin{array}{c}\text { Aeromonas } \\
\text { Species }\end{array}$} & $\mathbf{N}$ & \multicolumn{3}{c}{$\%$ of Fish with Histopathological Lesions } \\
\cline { 3 - 5 } & & Rosette & Telencephalon & Oblongata Medulla \\
\hline A. & & 30 & 3.3 & 1.1 \\
allosaccharophila & 90 & 26.6 & 21.1 & 40 \\
A. bestiarum & 90 & 28.8 & 22.2 & 16.6 \\
A. caviae & 90 & 27.7 & 18.8 & 22.2 \\
A. hydrophila & 90 & 50 & 18.8 & 22.2 \\
A. lusitana & 90 & 35.5 & 31.1 & 22.2 \\
A. media & 90 & 7.7 & 3.3 & 4.4 \\
A. popoffii & 90 & 41.1 & 25.5 & 15.5 \\
A. salmonicida & 90 & 20 & 7.7 & 12.2 \\
A. sobria & 90 & 11.1 & 10 & 17.7 \\
A. veronii & 90 & 0 & 0 & 0 \\
Control group & 90 & &
\end{tabular}

${ }^{1}$ Groups in italics within the same column are significantly different $(p<0.05)$.

On the other hand, the histopathological findings in the oblongata medulla were focal and multifocal congestion, and moderate-to-severe degrees of infection with $A$. bestiarum $(40 \%)$. No significant histopathological lesions $(p>0.05)$ were observed for the groups infected with the species $A$. hydrophila, A. lusitana, and A. media, A. veronii, A. caviae, A. salmonicida, A. sobria, A. popoffii, and A. allosaccharophila (Table 3). The fingerling group infected with $A$. salmonicida presented a mild degree and focal congestion with perivascular mononuclear infiltrate were identified in one fingerling (Figure 1d), but basophilic aggregates were not observed. The percentages of bacterial isolation were obtained from the region in cerebellum and medulla oblongata. Fingerlings were infected with $A$. bestiarum $(0.90 \%)$, A veronii and A. media $(0.80 \%)$, A. lusitana and A. popoffii $(0.60 \%)$, A. salmonicida $(0.30 \%), A$. hydrophila $(0.10 \%)$, but were not statistically representative; bacterial isolation of A. allosaccharophila, A. caviae, A. sobria and the control group were not obtained (data not shown).

\subsection{Correspondence Analysis}

To identify the associations between the Aeromonas species and histopathological lesions and behavioral changes two correspondence analysis (CA) were implemented. $\mathrm{CA}$ is an exploratory analysis that reduces the complexity of the initial database while retaining most information and providing the graphical output's relationships, favoring their interpretation. Table 4 depicts the results of $X^{2}$ analysis, which reveals a strong dependency $(p<0.001)$ between Aeromonas species with histopathological lesions and behavioral changes.

Table 4. Results of $X^{2}$ analysis of histopathological lesions and behavioral changes observed in rainbow trout fingerlings infected with several Aeromonas species.

\begin{tabular}{ccc}
\hline Item & Histopathological Lesions & Behavioral Changes \\
\hline$X^{2}$ (observed value) & 68.20 & 123.64 \\
$X^{2}$ (critical value) & 31.41 & 31.41 \\
$D F$ & 20 & 20 \\
$p$-value & 0.0001 & 0.0001 \\
$\alpha$ & 0.05 & 0.05 \\
\hline
\end{tabular}

To the histopathological lesions CA, the first and second dimensions account for 79.94 and 20.05 percent of inertia, respectively; both dimensions represent for $100 \%$ of cumulative inertia, indicating that the totality of variability was explained by the information contained within the first two axis (Table 2). The CA focused on behavioral changes associates with 
Aeromonas species reveals that the two dimensions provides an adequate description of data. The first dimension accounts for $71.17 \%$ and, for the second dimension, $28.82 \%$ of inertia, together accounting for $100 \%$ of the variability of analyzed data (Table 5).

Table 5. Dimension inertia of correspondence analysis of histopathological lesions and behavioral changes observed in rainbow trout fingerlings infected with several Aeromonas species.

\begin{tabular}{ccc}
\hline Item & \multicolumn{3}{c}{ Histopathological Lesions } \\
\hline Eigen value & 0.079 & 0.020 \\
Inertia (\%) & 79.94 & 20.05 \\
Cumulative (\%) & 79.94 & 100.00 \\
\hline Item & \multicolumn{3}{c}{ Behavioral changes } \\
\hline Eigen value & Dimension 1 & Dimension 2 \\
Inertia (\%) & 0.095 & 28.82 \\
Cumulative (\%) & 71.17 & 100.00 \\
\hline
\end{tabular}

Figure 2a shows CA maps of histological lesions and the quality of representation in the row and columns of the first dimension. The most of Aeromonas species are well represented, with the exception of A. popoffii, A. sobria, and A. hydrophila. With respect to the site of lesions, the telencephalon category showed a low quality of representation; therefore, the first dimension explains most of the deviation from the expected values of categories oblongata medulla and nasal epithelium. This means that the variability of first component can be explained by differences between oblongata medulla and nasal epithelium. According to the level of contribution of column categories of CA map of behavioral changes, the first dimension can be explained by a negative correlation among $A$. veronii and A. salmonicida (allocated in negative pole) with A. lusitana and A. popoffii (allocated in positive pole). On other hand, A. hydrophila and A. bestiarum showed a poor representation, had a lower contribution, and was allocated near to the centroid. The contribution of row to the definition of the first dimension is shown in Figure $2 b$. The category hyperpigmentation shows the highest contribution to define the first dimension. However, inertia of databases can be better explained by the opposition of hyperpigmentation and inappetence of the second dimension. Finally, swimming abnormal behavior showed the lowest contribution, little representation on the AC map, and was close to centroid.

The higher proportion of inertia explained by the first two dimensions in both CAs allows the proper interpretation of biplots shown in the Figure 2a and b. In the biplot of histopathological lesion CA, we see that $A$. popoffii and A. hydrophila are close to the origin point (Figure 3a). Therefore, we can conclude that these Aeromonas species cannot be different based on data from our study. Oblongata medulla and telencephalon are away from the origin; hence, these are good discriminators between Aeromonas species. $A$. bestiarum and $A$. veronii species are close to oblongata medulla lesions and the angle formed for these categories is very small, which means that they are associated. According to the CA biplot, lesions on telencephalon are associated with A. media and A. caviae species. Based on the angle formed by olfactory epithelium and A. allosaccharophila, we can conclude that they are closely associated. Lower strength of association is depicted between olfactory epithelium lesions and control and A. lusitana species. A. salmonicida and A. sobria species did not show a particular site of lesions based on analyzed data. And finally, the Figure $3 b$ showed the biplot of CA focused on behavioral changes, which displays that changes of behavior are clearly separated. Hyperpigmentation and inappetence are located far to the centroid and can be a good discriminator between Aeromonas species. This means that most Aeromonas species can be grouped according to the type of affection on behavior. A. veronii and A. salmonicida are located on the left-hand side of the graph and according to their angles are strongly associated with hyperpigmentation changes. Abnormal swimming is located on the right-side of biplot and their manifestation in infected animals is considerably associated with A. lusitana, A. allosaccharophila, and A. 
popoffii species. Inappetence changes showed an adequate representation to be far to the centroid; however, the exhibiting of these changes was not associated with a specific Aeromonas species, with a slight relationship with A. media, A. caviae, and A. sobria species.
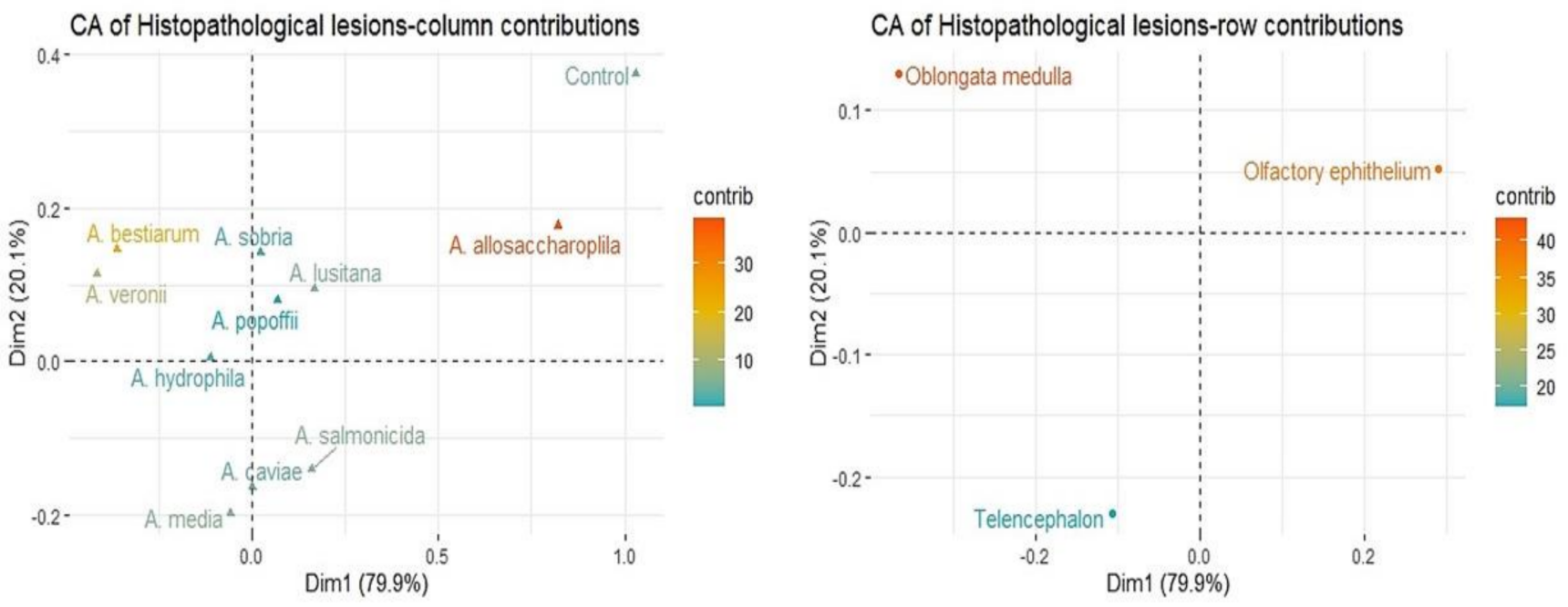

(a)


(b)

Figure 2. Correspondence analysis map. (a) Histopathological lesions and quality of representation to row and columns of dimen-sion 1; (b) behavioral changes and quality of representation to row and columns of dimension 1 . The row and column categories are color coded according with the contribution to dimension 1. 


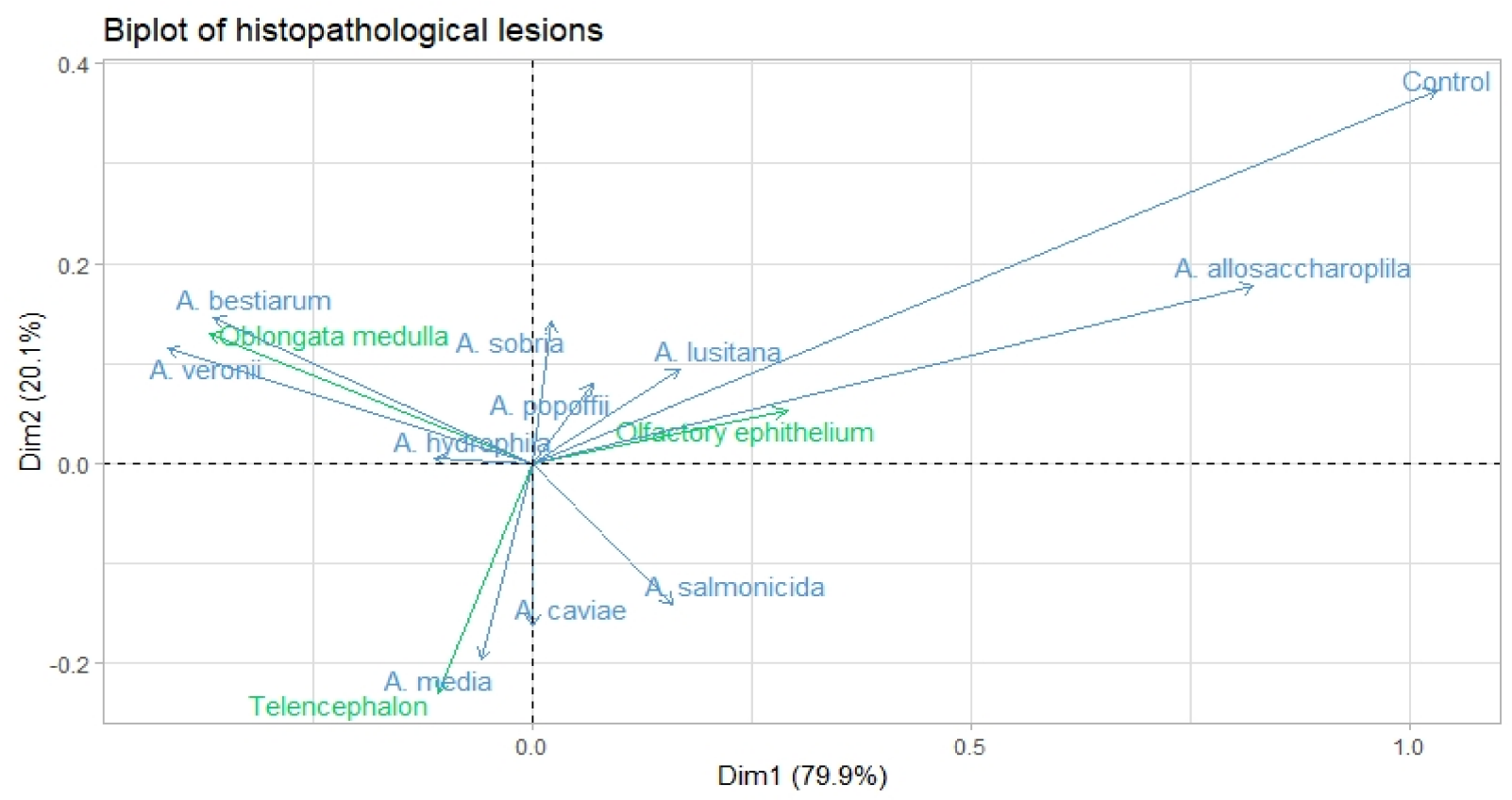

(a)

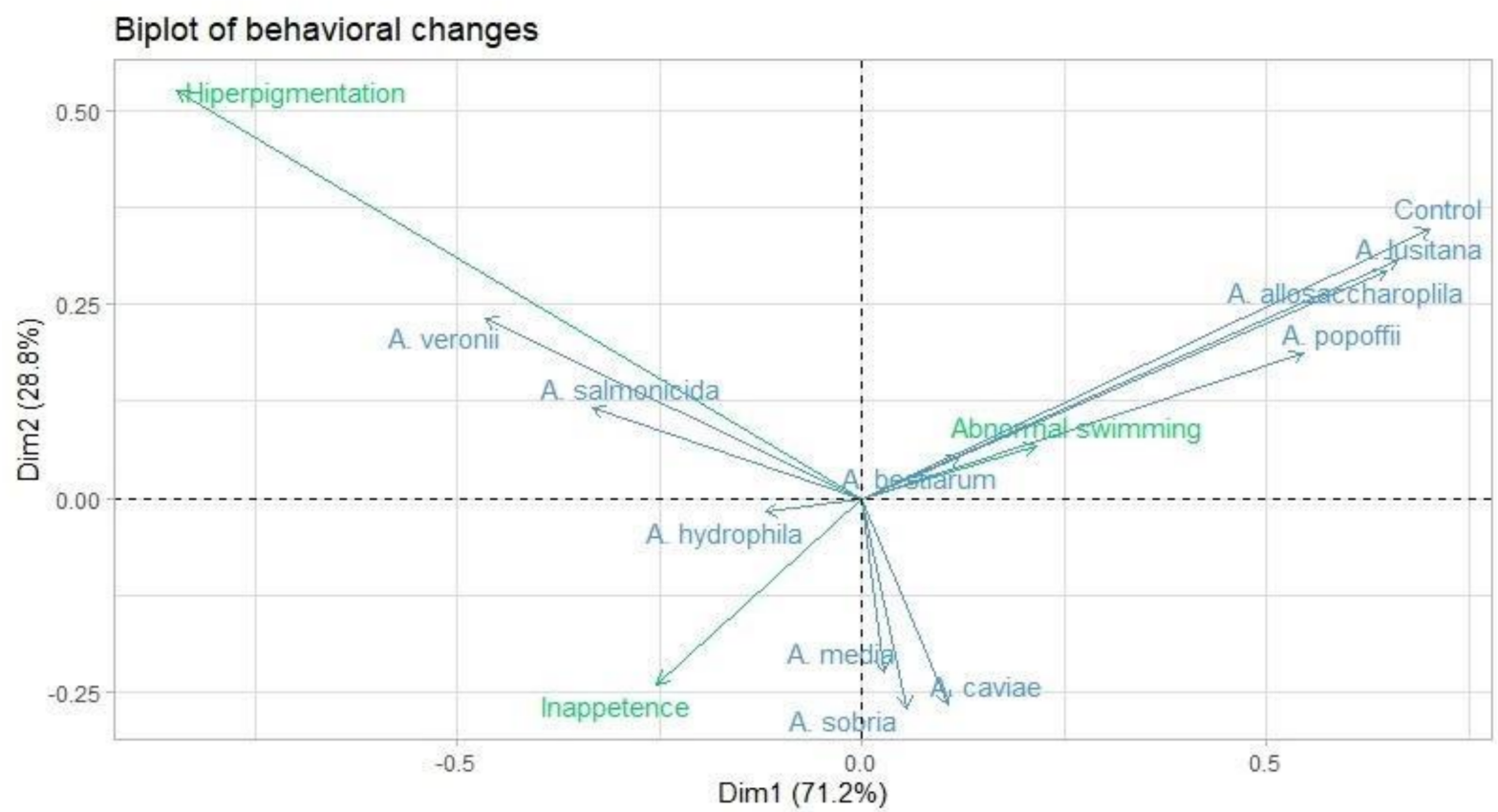

(b)

Figure 3. Bioplot analysis map. (a) Histopathological tissue localization and the histopathological lesions produce by different Aeromonas species in rainbow trout fingerlings of representation to row and columns of dimension 1 ; (b) behavioral changes observed in fingerlings experimentally infected with different Aeromonas species and quality of representation to row and columns of dimension 1.

\section{Discussion}

The genus Aeromonas is a group of bacteria that are widely distributed in different ecosystems, such as different types of food, animals (dogs, cats, horses, fish, mollusks, among others), infections in humans (gastritis, skin infections, bacteremia/septicemia processes, among others) and aquatic [6]. It is well known that the development of disease, and the clinical manifestations in a living organism, depend mainly on the susceptibility and immunity of the host, the virulence of the pathogenic agent and the environmental 
conditions, which result in an alteration of the homeostasis of the host and, therefore, the state of disease [22].

The nasal route of fish, also known as the rosette, is composed of pseudostratified epithelium, which contains mucous portions, sensory and vascular tissue; and it's one of the entry routes that different pathogens can use to infect and colonize the host and that has the ability to establish an innate immune response [13].

In the experimental infection of fingerlings with different Aeromonas species, the presence of histological lesions in the rosette were observed, mainly of the vascular type, identifying hemorrhages with different degrees of severity and distribution, as well as goblet cell hyperplasia in different degrees of severity and polymorphonuclear leucocyte infiltrates. This acute inflammatory response was observed in fish infected with the species of A. lusitana, A. allosaccharophila, A. popoffii, and A. sobria, these species being the ones that caused severe histological lesions. On the other hand, the fish infected with $A$. bestiarum, $A$. caviae, A. hydrophila, A. media, and A. salmonicida, the lesions were slight; the control group did not present histopathological lesions.

Salinas et al., [14] observed that the administration of a nasal vaccine against infectious hematopoietic necrosis and enteric red mouth disease, inducing histological changes in nasal tissue, identifying infiltrates of leukocytes in different severity degrees and the presence of vascular changes, related to the inflammatory process, without the presentation of hemorrhages.

The histological findings present in this work were consistent with Lapatra et al. [13], who carried out the nasal infection of the infectious hematopoietic necrosis and enteric red mouth disease, infecting each nostril separately, to implement a vaccination strategy, goblet cell hyperplasia, leukocyte infiltrate and vascular changes were observed in the nasal tissue, which consisted in the formation of new tissue.

It was reported that the bacterium needs a second site of infection, the presentation of meningitis and encephalitis in salmonid species infected with Renibacterium salmoninarum is localized to sites with greater blood supply, including the heart, reticuloendothelial organ, and encephalon, as observed in asymptomatic fish [28]. The presentation of hemorrhages and the inflammatory response in the rosette, against the experimental infection by immersion with different Aeromonas species, demonstrated that it i not only the vascular change derived from the inflammatory response, but also of the capacity of each Aeromonas species to possess its own pathogenicity and virulence capacity.

The olfactory system of all vertebrates is made up of sensory neurons; in fish, the rosette is attached to the olfactory bulb by terminal axons, which project from the olfactory tract to different parts of the brain [29]. In the present work, the olfactory bulb was not analyzed histologically due to the size of the trout fingerlings. Ye et al. [30] identified that the olfactory bulb has an important role in the detection of pathogens, as well as in the regulation of the immune response in addition to identifying the genes that are responsible for the secretion of inter-leucine (IL) $1 \beta$ and IL-8, present during the inflammation process. Song et al. [31] identified that part of the inflammatory response due to A. hydrophila infection in the intestine is closely related to the expression of IL8 and IL1 $\beta$ levels. This suggests that infection with Aeromonas species can infect the nasal route, and the nasal route has an important role in the early stages of infection and triggers the immune response, however more studies are needed to accept this hypothesis.

The production of vaccines in the aquaculture industry is focused on the stimulation of humoral immunity, by stimulating the mucosal immune response present in the mucosal tissue distributed in the body, while the intranasal application of vaccines in fish has generated, step by step, a fertile field as an alternative route of immunization in aquaculture [14]. In the case of Aeromonas spp., active and inactive vaccines were administered by immersion bath or intraperitoneally [32]. Therefore, due to the clinical importance of some Aeromonas species, they could be candidates for use in the generation of bacterins. As in the case of infectious hematopoietic necrosis and enteric red mouth disease [13]; however, more 
studies are needed to support this hypothesis, so this work will serve as a basis for future studies.

The presence of sensory neurons in the rosette, and their connection between the olfactory bulb and the brain, suggest they can induce alterations in feeding behavior, reproductive behavior and alarm reactions [29]. The histopathological findings in telencephalon consisted of moderate multifocal congestion for fish infected with $A$. media, and a moderate-to-severe degree for the groups infected by $A$. salmonicida, A. bestiarum, A. caviae, A. hydrophila, and $A$. lusitana, which presented moderate focal congestion; and, in the oblongata medulla were focal and multifocal congestion, and moderate to severe degrees of infection with $A$. bestiarum and $A$. veronii. No significant histopathological lesions $(p>0.05)$ were observed for the groups infected with the species $A$. allosaccharophila, $A$. caviae, A. hydrophila, A. lusitana, A. media, A. popoffii, A. sobria, and the control group.

The telencephalon in teleost participates in appetite regulation factors and the regulation of hormone inducing genes, such as corticotrophin releasing hormone 1a, which causes an anorectic effect; and adrenergic receptors, which participate in sex-specific swimming behavior [30]. On the other hand, the medulla oblongata participates in progressive hearing loss, in balance disorders and in the feeding role of fish [33]. Strom et al. [16] demonstrated that experimental infection with Yersinia ruckeri $\mathrm{O} 1$ biotype 2 causes lesions in the nasal epithelium and nervous system of fish infected via an immersion bath; this shows that bacterial pathogenesis begins with direct contact of the pathogen and the nasal epithelium close to the nervous system, causing problems in coordination and abnormal behavior. In the control group, the presence of congestion in the nasal epithelium was observed in two small fingerlings, because the hierarchy behavior of trout at feeding or the social status in the aquarium cause injuries in some subordinated rainbow trout; this induces stress by the biogenesis of cortisol [34].

The color change in teleost can be caused by multiple factors, stress being one of the main ones; continuous stress favors an increase in the secretion of the hormone cortisol, adrenocorticotropic hormone and alpha melanophore-stimulating hormone (Msh), which increases the number of chromophores and favors the presentation of skin darkening in stressed fish [35]. In the present study, hyperpigmentation or darkened skin was observed in fish infected with the species of $A$. salmonicida $(18.8 \%)$ (Figure 1a), A. veronii (15.5\%), and A. hydrophila (11.1\%). In a study carried out by Aydin and Ciltas [19], the experimental infection of $A$. hydrophila in rainbow trout, which presented darkening skin, anorexia, abnormal movements, as well as other authors, who observed similar signology (Table 1). However, in the case of $A$. salmonicida, hyperpigmentation or darkened skin is not frequently reported as a clinical sign. In the case of $A$. veronii, it was reported that dying fish have pale dermis [36].

Other factors that induce skin color change in fish include biotic and abiotic external factors as nutrition, social interactions, luminosity, and UV incidence; individual genetic factors, cellular responses, nervous and hormonal responses [35]. Darkening or pale skin of fish infected with different species of Aeromonas, should not be considered as clinical signs of the disease.

In clinical case reports of fish infected with Aeromonas spp., it was reported that fish may present anorexia and abnormal swimming, sometimes described as swimming near the water surface [37]. Wang et al. [1] reported that fish naturally infected with $A$. veronii showed changes in their way of swimming, described as slow movements of diseased fish. The results of this work, reported that fingerlings infected with A. bestiarum, A. caviae, A. hydrophila, A. salmonicida, and A. sobria, are the species that cause erratic swimming (Tables 1 and 2). Histological findings and behavioral changes were identified in fish infected by $A$. salmonicida and $A$. bestiarum, the most pathogenic and virulent species. Although the presence of basophilic aggregates was not observed in nervous tissue, the bacterial isolation of the species A. bestiarum, A. veronii, A. media, A. lusitana, A. popoffii, $A$. salmonicida, and $A$. hydrophila was obtained (data not shown). This agrees with Bartkova et al., [15] who reported the isolation of the kidney, spleen and brain from 
fish infected by immersion, and the distribution of A. salmonicida in dorsal, pectoral, and caudal area; anal fin, anal opening, gills, oral and nasal mucosa; and in eyes, without the presence of basophilic aggregates in the tissue.

The absence of bacterial structures in the histological sections of nerve tissue suggests the participation of virulence factors present in the Aeromonas genus, among them: the production of lipopolysaccharides (LPS), which favor the differences in virulence between the different species and the nonspecific inflammatory response due to the differences between the O-antigen LPS; the $\mathrm{S}$ layer that is related to the pathogenicity functions, the hemolysis that cause the formation of pores in the target cell; and proteases that also favor bacterial pathogenicity and the promotion of bacterial invasion, through direct damage due to the activation of proteolytic toxins [6].

\section{Conclusions}

Based on the identification of histopathological lesions of rainbow trout fingerlings infected with different Aeromonas species, it was observed that the species with the greatest capacity to cause the presentation of suppurative rhinitis are A. allosaccharophila, A. lusitana, A. popoffii and, A. sobria. While the species of A. bestiarum, A. veronii, and A. hydrophila, possess the ability to generate vascular changes in telencephalon; and the species of $A$. media, A. caviae, and A. salmonicida, cause vascular changes in medulla oblongata, in both cases, these nervous tissues are linked to the behavioral changes and clinical signs identified in experimentally infected fish. This suggests the pathogenic and virulent ability of the bacteria to establish itself in the nasal epithelium and affect the nervous system.

Author Contributions: Conceptualization, A.P.Z.-V. and R.G.C.-M.; methodology, V.V.-S.; software, J.C.Á.-H.; validation, N.E.R.-R., F.R.G.d.A., V.M.M.-J., I.A.-R. and V.V.-S.; formal analysis, J.C.Á.-H.; investigation, V.M.M.-J. and I.A.-R.; data curation, J.C.Á.-H. and A.P.Z.-V.; writing—original draft preparation, A.P.Z.-V.; writing-review and editing, A.P.Z.-V. and R.G.C.-M.; visualization, N.E.R.-R. and V.V.-S.; supervision, A.P.Z.-V. All authors have read and agreed to the published version of the manuscript.

Funding: This research received no external funding.

Institutional Review Board Statement: The study was conducted according to the guidelines of the Declaration of Helsinki and approved by the Bioethics Commission and Animal Welfare Committee (Comisión de Bioética y Bienestar animal, CBBA) of the Universidad Autónoma del Estado de México (UAEMex), Facultad de Medicina Veterinaria y Zootecnia (FMVZ) (012-2012).

Informed Consent Statement: Not applicable.

Data Availability Statement: Not applicable.

Acknowledgments: This investigation study was realized in CIESA installations (Centro de Investigación y Estudios Avanzados en Salud Animal) of the Universidad Autónoma del Estado de México. We appreciate the support of Edgardo Soriano-Vargas, in this research work.

Conflicts of Interest: The authors declare no conflict of interest.

\section{References}

1. Wang, B.; Mao, C.; Feng, J.; Li, Y.; Hu, J.; Jiang, B.; Gu, Q.; Su, Y. A First report of Aeromonas veronii infection of the sea bass, Lateolabrax maculatus in China. Front. Veter-Sci. 2021, 7, 600587. [CrossRef]

2. Srivastava, A.; Mistri, A.; Mittal, S.; Kumar, A.M. Alterations in the epidermis of the carp, Labeo rohita (Cyprinidae: Cypriniformes), infected by the bacteria, Aeromonas hydrophila: A scanning electron microscopic, histopathological and immunohistochemical investigation. J. Fish Dis. 2020, 43, 941-953. [CrossRef]

3. Janda, J.M.; Abbott, S.L. The genus Aeromonas: Taxonomy, pathogenicity, and infection. Clin. Microbiol. Rev. 2010, $23,35-73$. [CrossRef] [PubMed]

4. Huber, I.; Spanggaard, B.; Appel, K.F.; Rossen, L.; Nielsen, T.; Gram, L. Phylogenetic analysis in situ identification of the in-testinal microbial community of rainbow trout (Oncorhynchus mykiss, Walbaum). J. Appl. Microbiol. 2004, 96, 117-132. [CrossRef] [PubMed]

5. Austin, B.; Austin, D.A. Bacterial Fish Pathogens, Diseases of Farmed and Wild Fish, 4th ed.; Praxis Publishing Ltd.: Chichester, UK, 2007; pp. 123-153. 
6. Fernández-Bravo, A.; Figueras, M.J. An update on the genus Aeromonas: Taxonomy, epidemiology, and pathogenicity. Microorganisms 2020, 8, 129. [CrossRef] [PubMed]

7. Dallaire-Dufresne, S.; Tanaka, K.H.; Trudel, M.V.; Lafaille, A.; Charette, S.J. Virulence, genomic features, and plasticity of Aeromonas salmonicida subsp. salmonicida, the causative agent of fish furunculosis. Veter-Microbiol. 2014, 169, 1-7. [CrossRef] [PubMed]

8. Zepeda-Velázquez, A.P.; Sánchez, V.V.; Ortega-Santana, C.; Rubio-Godoy, M.; de Oca-Mira, D.M.; Soriano-Vargas, E. Pathogenicity of Mexican isolates of Aeromonas sp. in immersion experimentally-infected rainbow trout (Oncorhynchus mykiss, Walbaum 1792). Acta Trop. 2017, 169, 122-124. [CrossRef] [PubMed]

9. Fuentes, R.J.M.; Pérez, H.J.A. Aislamiento de Aeromonas hydrophila en truchas Arcoíris (Oncorhynchus mykiss). Vet. Méx. 1998, 29, 117-119.

10. Zepeda-Velázquez, A.P.; Vega-Sánchez, V.; Salgado-Miranda, C.; Soriano-Vargas, E. Histopathological findings in farmed rainbow trout (Oncorhynchus mykiss) naturally infected with 3 different Aeromonas species. Can. J. Vet. Res. 2015, 79, $250-254$.

11. Marinho-Neto, F.A.; Claudiano, G.S.; Aguinaga, J.Y.; Quiroz, V.A.C.; Kobashigawa, K.K.; Cruz, N.R.N.; Moraes, F.R.; Moraes, J.R.E. Morphological, microbiological and ultrastructural aspects of sepsis by Aeromonas hydrophila in Piaractus mesopotamicus. PLoS ONE 2019, 14, e0222626. [CrossRef] [PubMed]

12. Noga, E.J. Fish Disease, Diagnosis, and Treatment, 2nd ed.; Wiley-Blackwell: Iowa, IA, USA, 2010.

13. LaPatra, S.; Kao, S.; Erhardt, E.B.; Salinas, I. Evaluation of dual nasal delivery of infectious hematopoietic necrosis virus and enteric red mouth vaccines in rainbow trout (Oncorhynchus mykiss). Vaccine 2015, 33, 771-776. [CrossRef] [PubMed]

14. Salinas, I.; LaPatra, S.; Erhardt, E. Nasal vaccination of young rainbow trout (Oncorhynchus mykiss) against infectious hematopoietic necrosis and enteric red mouth disease. Dev. Comp. Immunol. 2015, 53, 105-111. [CrossRef]

15. Bartkova, S.; Kokotovic, B.; Dalsgaard, I. Infection routes of Aeromonas salmonicida in rainbow trout monitored in vivo by real-time bioluminescence imaging. J. Fish Dis. 2017, 40, 73-82. [CrossRef]

16. Strøm, H.K.; Ohtani, M.; Nowak, B.; Boutrup, T.S.; Jones, B.; Raida, M.K.; Bojesen, A.M. Experimental infection by Yersinia ruckeri O1 biotype 2 induces brain lesions and neurological signs in rainbow trout (Oncorhynchus mykiss). J. Fish Dis. 2017, 41, 529-537. [CrossRef]

17. Farto, R.; Milton, D.L.; Bermúdez, M.B.; Nieto, T.P. Colonization of turbot tissues by virulent and avirulent Aeromonas salm-onicida subsp salmonicida strains during infection. Dis. Aquat. Organ. 2011, 95, 167-173. [CrossRef]

18. Nordgreen, J.; Tahamtani, F.M.; Janczak, A.M.; Horsberg, T.E. Behavioural effects of the commonly used fish anaesthetic tricaine methanesulfonate (MS-222) on zebrafish (Danio rerio) and its relevance for the acetic acid pain test. PLoS ONE 2014, 9, e92116. [CrossRef]

19. Aydin, S.; Çiltaş, A. Systemic infections of Aeromonas hydrophila in rainbow trout (Oncorhynchus mykiss Walbaum): Gross pathology, bacteriology, clinical pathology, histopathology, and chemotherapy. J. Anim. Vet. Adv. 2004, 3, 810-819.

20. Aydoğan, A.; Metin, N. Investigation of pathological findings infected with Aeromonas salmonicida in rainbow trout (Oncorhynchus mykiss Walbaum, 1972). Kafkas Univ. Vet. Fak Derg 2010, 16, S325-S328.

21. Inglis, V.; Roberts, R.J.; Bromage, N.R. Bacterial Diseases of Fish, 1st ed.; Iowa State University Press: Iowa City, IA, USA, 1993; pp. 80-121.

22. Lago, E.P.; Nieto, T.P.; Farto, R. Virulence factors of Aeromonas salmonicida subsp. salmonicida strains associated with infections in turbot Psetta maxima. Dis. Aquat. Org. 2012, 99, 145-151. [CrossRef] [PubMed]

23. Roberts, R.J. Fish Pathology, 3rd ed.; Wiley-Blackwell: Iowa, IA, USA, 2001.

24. Miller, K.M.; Günther, P.O.; Li, S.; Kaukinen, H.K.; Ming, J.T. Molecular indices of viral disease development in wild migrating salmon. Conserv Physiol. 2017, 5, cox036. [CrossRef] [PubMed]

25. Lê, S.; Josse, J.; Husson, F. FactoMineR: An R package for multivariate analysis. J. Stat. Softw. 2008, 25. [CrossRef]

26. R Core Team. R: A Language and Environment for Statistical Computing. R Foundation for Statistical Computing. Vienna, Austria, 2013.

27. Kassambara, A.; Mundt, F. Factoextra: Extract and visualize the results of multivariate data analyses. $R$ Package Version 2017, 1, 337-354.

28. Speare, D. Differences in patterns of meningoencephalitis due to bacterial kidney disease in farmed Atlantic and chinook salmon. Res. Veter-Sci. 1997, 62, 79-80. [CrossRef]

29. Hamdani, E.H.; Døving, K.B. The functional organization of the fish olfactory system. Prog. Neurobiol. 2007, 82, 80-86. [CrossRef] [PubMed]

30. Ye, C.; Xu, S.; Hu, Q.; Hu, M.; Zhou, L.; Qin, X.; Jia, J.; Hu, G. Structure and function analysis of various brain subregions and pituitary in grass carp (Ctenopharyngodon idellus). Comp. Biochem. Physiol. Part D Genom. Proteom. 2020, 33, 100653. [CrossRef] [PubMed]

31. Song, X.; Zhao, J.; Bo, Y.; Liu, Z.; Wu, K.; Gong, C. Aeromonas hydrophila induces intestinal inflammation in grass carp (Ctenopharyngodon idella): An experimental model. Aquaculture 2014, 434, 171-178. [CrossRef]

32. Bøgwald, J.; Dalmo, R.A. Review on Immersion Vaccines for Fish: An Update. Microorganisms 2019, 7, 627. [CrossRef] [PubMed]

33. Yang, Y.; Wang, X.; Liu, Y.; Fu, Q.; Tian, C.; Wu, C.; Shi, H.; Yuan, Z.; Tan, S.; Liu, S.; et al. Transcriptome analysis reveals enrichment of genes associated with auditory system in swim bladder of channel catfish. Comp. Biochem. Physiol. Part D Genom. Proteom. 2018, 27, 30-39. 
34. Kostyniuk, D.J.; Culbert, B.M.; Mennigen, J.A.; Gilmour, K.M. Social status affects lipid metabolism in rainbow trout, Oncorhynchus mykiss. Am. J. Physiol. Integr. Comp. Physiol. 2018, 315, R241-R255. [CrossRef] [PubMed]

35. Vissio, P.G.; Darias, M.J.; Di Yorio, M.P.; Sirkin, D.I.P.; Delgadin, T.H. Fish skin pigmentation in aquaculture: The influence of rearing conditions and its neuroendocrine regulation. Gen. Comp. Endocrinol. 2021, 301, 113662. [CrossRef] [PubMed]

36. Dong, H.T.; Techatanakitarnan, C.; Jindakittikul, P.; Thaiprayoon, A.; Taengphu, S.; Charoensapsri, W.; Khunrae, P.; Rattanarojpong, T.; Senapin, S. Aeromonas jandaei and Aeromonas veronii caused disease and mortality in Nile tilapia, Oreochromis niloticus (L.). J. Fish Dis. 2017, 40, 1395-1403. [CrossRef] [PubMed]

37. Sreedharan, K.; Philip, R.; Sarojani, I.; Singh, B. Characterization, and virulence potential of phenotypically diverse Aeromonas veronii isolates recovered from moribund freshwater ornamental fishes of Kerala, India. Antonie Van Leeuwenhoek 2013, $103,53-67$. [CrossRef] 